\title{
PARTISIPASI MASYARAKAT DALAM PENGELOLAAN HUTAN KEMASYARAKATAN (HKm) TANDUNG BILLA DI KELURAHAN BATTANG KOTA PALOPO
}

\author{
Community Participation in the Existence of Community Forest $(\mathrm{Hkm})$ Tandung Billa in Battang \\ and Battang Barat Sub-District, Palopo City. \\ Witno $^{1}$, Maria $^{2}$, Dicky Supandi ${ }^{3}$ \\ Program Studi Kehutanan Fakultas Kehutanan Universitas Andi Djemma Palopo, Kampus \\ Agrokompleks Unanda, Palopo 19211 \\ e-mail:witnosanganna@gmail.com
}

\begin{abstract}
In efforts to realize sustainable forest management, it is necessary to involve the community around the forest as the main actors who often interact with the forest. In this case, the concept in question is the concept of community participation. This study aims to determine the participation of forest communities in the existence of community forests. This research was conducted in Battang Village, West Wara District, Palopo City, South Sulawesi Province. Data obtained directly through surveys and direct field observations, data collected through observation, and semi-structured interviews are processed and clarified according to the research objectives and then analyzed using qualitative data analysis. The results obtained are that community participation in the management of the Community Forest (Hkm) Tandung Billa is low. Several factors contributed to the lack of skills, experience, and opportunities for members in managing KUPS. This condition is obtained from the community's participation in planning totaling 137 people, from implementation to the evaluation stage totaling 35 people. This was due to contradictory plans and conditions in the field that triggered problems within the group.
\end{abstract}

Keywords: Community Forestry, Community Participation, Tandung Billa Palopo

\begin{abstract}
ABSTRAK
Upaya mewujudkan konsep pengelolaan hutan yang lestari, maka perlu melibatkan masyarakat sekitar hutan selaku pelaku utama yang sering berinteraksi dengan hutan. Dalam hal ini, konsep yang dimaksud merupakan konsep partisipasi masyarakat. Penelitian ini bertujuan untuk mengetahui partisipasi masyarakat sekitar hutan terhadap keberadaan Hutan Kemasyarakatan. Penelitian ini dilaksanakan di Kelurahan Battang, Kecamatan Wara Barat, Kota Palopo, Provinsi Sulawesi Selatan. Data diperoleh secara langsung melalui survey dan pengamatan langsung dilapangan, data yang dikumpulkan melalui metode observasi dan wawancara semi terstruktur diolah dan diklarifikasikan sesuai dengan tujuan penelitian lalu dianalisis dengan menggunakan analisis data kualitatif. Hasil yang di peroleh yaitu Partisipasi masyarakat dalam pengelolaan Hutan Kemasyarakatan $(\mathrm{Hkm})$ Tandung Billa tergolong rendah. Beberapa faktor yang menyebabkan yaitu kurangnya keterampilan, pengalaman dan kesempatan anggota dalam pengelolaan KUPS. Kondisi ini diperoleh dari partisipasi masyarakat dalam perencanaan berjumlah 137, pelaksanaan hingga tahap evaluasi berjumlah 35 orang. Hal ini karena bertolak belakangnya perencanaan dan kondisi yang ada di lapangan yang memicu permasalahan dalam kelompok.
\end{abstract}

Kata Kunci : Hutan Kemasyarakatan, Partisipasi Masyarakat, Tandung Billa Palopo 


\section{PENDAHULUAN}

Hutan merupakan sumberdaya yang menempati posisi yang sangat strategis dalam kehidupan berbangsa dan bernegara, sehingga dalam pengelolaan hutan yang berkelanjutan memerlukan sumber daya manusia yang berkualitas, berkemampuan IPTEK, serta manajemen yang baik. Dalam pemanfaatan sumber daya hutan dipengaruhi oleh beberapa factor diantaranya tingkat pendidikan masyarakat dan tingkat kemiskinan masyarakat sekitar yang masih sangat tinggi (Sagita et.al 2019). Dalam upaya mewujudkan konsep pengelolaan hutan yang lestari, maka perlu melibatkan masyarakat sekitar hutan selaku pelaku utama yang sering berinteraksi dengan hutan (Sanjaya, 2016). Dalam hal ini, konsep yang dimaksud merupakan konsep partisipasi masyarakat. Konsep partisipasi digunakan secara luas dalam wacana pembangunan dua puluh tahun terakhir ini. Dalam kurun waktu tersebut, konsep itu mengacu pada partisipasi dalam gelanggang sosial, masyarakat atau proyek pembangunan (Winata et.al. 2015). Namun kini konsep partisipasi semakin banyak dihubungkan dengan hak-hak kewargaan (citizenship) dan pemerintahan (governance) yang demokratis (The British Council, 2001).

Kondisi ini seperti halnya, dengan sistem pengelolaan hutan kemasyarakatan yang menempatkan masyarakat sebagai pengelola di tingkat tapak yang disebut dengan konsep partisipasi. Konsep partispasi artinya melibatkan masyarakat sebagai bentuk dari bagian kawasan hutan sekitarnya (Zeilika, 2020). Tentunya konsep partisipasi memerlukan peran penyuluh untuk bisa terampil dan berpengatahuan dalam mengelolah hutan. Hutan kemasyarakatan merupakan suatu sistem pengelolaan hutan yang ditujukan untuk meningkatkan kesejahteraan masyarakat di dalam dan di sekitar kawasan dengan tetap memperhatikan kelestarian fungsi hutan (Ayudanti, 2017).

Program ini merupakan program yang dirancang untuk meningkatkan pemberdayaan masyarakat sekitar hutan. Menurut Permenhut RI nomor.83/Menlhk/Sekjen/Kum.1/10/2016 tentang perhutanan sosial. Pemberdayaan masyarakat setempat adalah upaya untuk meningkatkan kemampuan dan kemandirian masyarakat setempat untuk mendapatkan manfaat sumber daya hutan secara optimal dan adil melalui pengembangan kapasitas dan pemberian akses untuk mengelola hutan (Safe'i et. al 2018). Menurut Permenhut RI Nomor P.83/Menlhk/Sekjen/Kum.1/10/2016 tentang perhutanan sosial. Hutan lindung Tandung Billa Kota Palopo merupakan kawasan hutan yang telah di tetapkan sebagai $\mathrm{HKm}$ berdasarkan Keputusan Menteri Lingkungan Hidup dan Kehutanan Republik Indonesia Tahun 2017 tentang Pemberian Izin Usaha Pemanfaatan Hutan Kemasyarakatan di tetapkan dalam SK.2628/Menlhk- Psk1/Pkps/Psl.0/5/2017. Kurun waktu tersebut, pengelolaan hkm telah melibatkan masyarakat secara langsung dalam mengelolah hutan. Sebagai bentuk dari upaya partisipasi masyarakat ini, kemudian dibentuk kelompok tani hutan (Gapoktanhut) Tandung billa. Gabungan kelompok tani hutan Tandung billa, tediri dari lima kelompok tani yang telah dilibatkan atau berpartisipasi mengelolah Hkm. Dalam pengelolaan Hkm memerlukan panelitian untuk mengetahui bagaimana partisipasi masyarakat, dalam mengelolah Hutan Kemasyarakatan(Hkm) khususnya Hkm Tandung Billa. Hal ini kemudian menarik untuk dilakukan penelitian lebih lanjut terkait partisipasi masyarakat terhadap keberadaan $\mathrm{Hkm}$ yang ada di Kelurahan Battang, Kecamatan Wara Barat, Kota Palopo, Provinsi Sulawesi Selatan.

\section{METODE PENELITIAN}

Penelitian ini dilaksanakan pada bulan Januari sampai Maret 2020, di Hutan Kemasyarakatan Tandung Billa, Kelurahan Battang, Kecamatan Wara Barat, Kota Palopo, Provinsi Sulawesi Selatan. Alat dan bahan yang digunakan dalam penelitian ini yaitu kuesioner yang dibagikan dan recorder/perekam suara untuk merekam proses wawancara. Populasi dalam penelitian ini adalah semua masyarakat yang ada di sekitar kawasan Hutan kemasyarakatan yang terdiri dari gabungan kelompok tani hutan tandung billa (Gapoktanhut tandung billa). Sedangkan sampel dari penelitian ini di tentukan secara purposive sampling yaitu beberapa anggota 
kelompok tani hutan yang ikut berpartisipasi secara langsung dalam pengelolaan $\mathrm{Hkm}$ Tandung Billa. Jumlah responden diukur dari banyaknya populasi yang apabila jumlah populasi kurang dari 100 maka lebih baik diambil semua sedangkan jika jumlah populasinya lebih dari 100 maka dapat diambil antara $10-20 \%$ dari banyaknya populasi (Arikunto, 2006).

Penelitian ini menggunakan analisis deskriptif kualitatif yaitu dengan menggambarkan dan mendeskripsikan faktafakta atau keadaan yang ada mulai dari sebelum memasuki lapangan, selama di lapangan dan setelah selesai di lapangan (Nasution 1988 dalam Sugiyono 2015). Analisis deskriptif lebih menekan pada hasil penelitian berupa wawancara langsung kepada responden yang sifatnya pendeskripsian secara utuh terhadap gambaran informasi yang diperoleh dari responden hasil wawancara. Data partisipasi masyarakat yang dianalisis berupa data pada tahap perencanaan, pelaksanaan dan evaluasi dengan dipengaruhi oleh tiga faktor yaitu faktor pemahaman, kesempatan dan evaluasi (Ruhimat, 2013).

\section{HASIL DAN PEMBAHASAN}

Hasil identifikasi melalui proses wawancara langsung di lapangan diketahui bahwa jumlah anggota secara keseluruhan adalah 137 orang. Jumlah ini juga berdasarkan pada SK pengelolaan $\mathrm{HKm}$ Tandung Billa, Kelurahan Battang dan Battang Barat. Jumlah responden yang dapat dijumpai dilapangan sejumlah 35 orang yang mewakili setiap KUPS (Kelompok Usaha Perhutanan Sosial). Jumlah ini, disebabkan karena yang aktif dalam tahap pelaksanaan hanya berjumlah 35 orang. Jumlah responden berdasarkan identitas jenis kelamin, tingkat pendidikan, umur, dan jenis pekerjaan dapat dilihat pada tabel berikut:

Tabel 1. Jumlah dan Karakteristik Responden Masyarakat di wilayah hutan kemasyarakatan Tandung Billa Kelurahan Battang.

\begin{tabular}{|c|c|c|c|}
\hline No & Karakteristik Responden & Jumlah (Orang) & Presentase (\%) \\
\hline 1 & Jenis Kelamin & & $74 \%$ \\
& Laki-Laki & 31 & $26 \%$ \\
\hline 2 & Perempuan & 4 & $22 \%$ \\
& Tingkat Pendidikan & & $41 \%$ \\
& SD & 7 & $29 \%$ \\
& SMP & 17 & - \\
\hline 3 & SMA & 8 & - \\
& S1 & 3 & - \\
& Umur & 6 & - \\
\hline 4 & $23-35$ & 10 & $88,6 \%$ \\
& $36-45$ & 12 & $8,6 \%$ \\
& $46-55$ & 7 & $5,7 \%$ \\
\hline
\end{tabular}

Sumber: Data Primer Setelah di Olah, 2019.

Hasil identifikasi bahwa responden dalam penelitian ini berjumlah 35 orang yang terdiri dari laki-laki dan perempuan. Responden yang berjenis kelamin laki-laki lebih banyak dibandingkan responden berjenis kelamin perempuan. Responden berjenis kelamin lakilaki sebanyak 31 orang (74\%); perempuan sebanyak 4 orang (26\%). Adanya mayoritas responden berjenis kelamin laki- laki ini menunjukkan tingkat partisipatif dan ketertarikannya terhadap keberadaan $\mathrm{HKm}$ lebih tinggi.

Berdasarkan Tabel 1, dapat dilihat bahwa dalam penelitian ini tingkat pendidikan responden yang paling banyak ikut berpartisipasi pada keberadaan HKm Tandung 
Billa yaitu SMP/sederajat sebanyak 17 orang atau sama dengan $41 \%$. Menurut Birgantoro dan Nurrochmat (2007) menyatakan bahwa tingkat pendidikan masyarakat juga dapat berpengaruh terhadap pengetahuan, penguasaan teknologi, keterampilan dan informasi pasar. Umur responden termuda adalah 23 tahun. Sedangkan tertua adalah 65 tahun. Hal ini menunjukkan bahwa masyarakat yang ikut berpartisipasi dalam keberadaan $\mathrm{HKm}$ termasuk dalam kategori umur dewasa dan lansia. Pekerjaan pokok responden adalah sebagai petani kebun yaitu 31 orang $(88,6 \%)$.

\section{Partisipasi Masyarakat}

\section{Tahap Perencanaan}

Perencanaan pengelolaan $\mathrm{HKm}$, tidak terlepas dari adanya faktor pendorong. Pada pengelolaan HKm Tandung Billa, terdapat tiga faktor pendorong yang memengaruhi partisipasi masyarakat yaitu pemahaman, kesempatan dan sikap. Penjabaran dari ketiga faktor ini dalam menentukan bentuk partisipasi masyarakat dapat dilihat dari beberapa skema perencanaan berikut.

- Perencanaan pengelolaan HKm Tandung Billa

Terdapat 5 kelompok tani hutan sebelum dibentuknya GAPOKTANHUT Tandung Billa. Kelompok Tani Hutan merupakan suatu lembaga yang menjadi media komunikasi antara anggota masyarakat yang dominan bermata pencaharian sebagai petani. Untuk mengembangkan kegiatan petani hutan, terutama dalam pemanfaatan sumber daya alam maka sarana informasi tentang kemajuan teknologi di bidang kehutanan sangat diperlukan.

Tabel 2. Kelompok Tani Hutan Tandung Billa.

\begin{tabular}{|c|c|c|c|}
\hline Nama Kelompok & Tahun Pembentuk & Jumlah Anggota & Jenis Kegiatan \\
\hline Batu tongkon & 2011 & 29 & Hasil hutan \\
\hline Mappatongko & 2011 & 30 & Lebah madu \\
\hline Tombarani & 2011 & 20 & Holtikultura \\
\hline Kalibambang & 2011 & 28 & Satwa liar \\
\hline Tandung billa & 2012 & 30 & Hasil hutan \\
\hline & Total & 137 & \\
\hline
\end{tabular}

Sumber: IUPHKM Palopo, 2017

Pengembangan hutan kemasyarakatan merupakan media belajar masyarakat Kelurahan Battang dalam mengelola kawasan hutan. Tahap awal terbentuknya kelembagaan (GAPOKTANHUT) terdiri dari 137 orang. Jumlah ini pada tahap awal pembentukan HKm turut dilibatkan dalam penyusunan lembaga $\mathrm{HKm}$. Namun seiring berjalannya waktu, kondisi keanggotaan semakin berkurang. Sehingga, penguatan kapasitas dan kelembagaan pengelolaan, dilakukan melalui berbagai kegiatan seperti pelatihan, workshop, diskusi, studi banding dan praktik langsung di lapangan. Pengembangan tempat pembibitan dan persemaian dimaksudkan untuk menghasilkan bibit secara mandiri. Bibit yang dihasilkan tersebut nantinya akan dimanfaatkan untuk kebutuhan budidaya dan rehabilitasi kawasan. Tempat pembibitan dan persemaian juga merupakan salah satu media belajar masyarakat dalam pelestarian dan pengembangan kawasan.

Rehabilitasi kawasan sebagian kawasan Hutan Lindung Battang merupakan lokasi ladang masyarakat Kelurahan Battang. Masih banyak terdapat lahan-lahan kritis serta pembukaan lahan baru yang tidak terkendali, hal ini menyebabkan fungsi hutan mulai berubah. Gapoktanhut Tandung Billa melihat hal ini tidak dapat terus dibiarkan, karena tepat di bawah kawasan hutan lindung Battang merupakan daerah pemukiman, hal ini dapat mengancam bencana longsor. Disisi lain sumber air yang berada tepat di hulu kawasan hutan lindung Battang merupakan sumber air bersih bagi warga masyarakat Kelurahan Battang. Dengan demikian, perlu dilakukan upaya rehabilitasi dan pengawasan terhadap Kawasan Hutan Lindung Battang. 
Volume 2 Nomor 2 Desember 2020:35-42

- Pengembangan Ekowisata

Bedasarkan Survei Potensi HHBK (Hasil Hutan Bukan Kayu) dan Ekowisata, kawasan hutan lindung Battang selain mempunyai potensi keanekaragaman jenis HHBK yang tinggi, juga mempunyai potensi wisata yang khas. Salah satu anggota Gapoktanhut sudah memasarkan kupu-kupu hingga ke mancanegara dan sudah mahir dalam membuat bingkai kupu-kupu. Selain itu, anggota Gapoktanhut Tandung Billa juga sudah ada yang memiliki keterampilan dalam membuat kerajinan yang terbuat dari rotan. Aktivitas budaya masyarakat Kelurahan Battang semakin sempurna dengan kondisi alamnya yang menyajikan keindahan dan kekayaan akan keanekaragaman hayati. Kawasan berhutan baik di hutan lindung Battang memiliki

ekowisata yang layak dikunjungi wisatawan. Terdapat empat air teriun dan puncak yang dapat menjadi lokasi wisata alam. Pengelolaan wisata di Hutan Lindung Battang selama ini masih belum dilakukan secara optimal, sehingga belum memberikan hasil yang maksimal bagi masyarakat. Dengan kekayaan alam dan budaya, maka dirasakan perlu melakukan pengembangan ekowisata di Kelurahan Battang.

- Perencanaan Usaha

Pembentukan Kelompok Usaha Perhutanan Sosial (KUPS) terdiri dari 9 kelompok usaha perhutanan sosial antara lain sebagai berikut:

Tabel 3. Nama-nama Kelompok Usaha Perhutanan Sosial.

\begin{tabular}{|c|c|}
\hline Nama KUPS & Anggota (Orang) \\
\hline Silvofishery Batu Tongkon & 16 \\
\hline Agrosilvikultur & 16 \\
\hline Agrosilvofastura & 16 \\
\hline Agrowisata Kali Bambang & 15 \\
\hline Agrosilvofishery Kalang & 15 \\
Gusi & 15 \\
\hline Apikultur Lambanan & 15 \\
\hline ( Kerajinan rotan tirowali ) & 15 \\
\hline Nursery & 14 \\
\hline ( Hkm mart ) & \\
\hline
\end{tabular}

Sumber: IUPHKM Palopo, 2017.

Tabel 3 menunjukkan data 9 Kelompok Usaha Perhutanan Sosial (KUPS) di Kelurahan Battang yang bergabung dalam GAPOKTANHUT Tandung Billa. Terdapat dua KUPS yang tidak aktif (Kerajinan Rotan Tirowali dan HKM Mart) disebabkan kurangnya sumber daya manusia untuk mengelolah hasil rotan maupun pembuatan produk-produk untuk dipasarkan. Selain itu, Kondisi ini juga karena KUPS yang terbentuk memiliki anggota yang masih pemula dengan keterampilan dan pengalaman yang masih kurang untuk kedua bidang tersebut. Upaya yang dilakukan oleh penyuluh GAPOKTANHUT Tandung Billa belum sepenuhnya maskimal sehingga perlu tingkatkan untuk menambah wawasan serta pengalaman para anggota KUPS. Upaya ini juga dinilai sebagai bentuk partisipasi masyarakat agar tujuan yang diharapkan menjadi maksimal.

\section{Tahap Pelaksanaan}

Partisipasi dalam pelaksanaan adalah keikutsertaan petani dalam pelaksanaan kegiatan $\mathrm{Hkm}$ yang dapat dilihat dari intensitas keikutsertaan petani dalam pelaksanaan pengelolaan. Dari hasil wawancara terhadap anggota kelompok tani hutan, kurang dilibatkan dalam kegiatan pengelolaan. Kondisi ini akibat manajamen yang kurang efektif dan kepercayaan oleh anggota kelompok tani kurang merefleksikan tindakan secara kolektif oleh seluruh anggota kelompok tani hutan (Yudischa et.al 2014). Sehingga usaha kemudian adalah meminimalisir kekurangan dengan senantiasa melibatkan seluruh anggota KUPS dalam setiap kegiatan pengelolaan dan 
memberikan kepercayaan penuh kepada anggota untuk melaksanakan setiap program secara kolektif.

Faktor pemahaman yang seharusnya mampu berkorelasi positif dengan faktor kesempatan dan sikap. Namun kemudian bertolak belakang dengan kondisi di lapangan. Faktor kesempatan anggota KUPS dalam mengelolah program kerja kurang dilibatkan. Justru kemudian faktor kesempatan dan sikap berkorelasi positif. Kondisi ini menjadi perhatian kedepannya, bahwa faktor kesempatan dan sikap yang positif harus berimbang dengan pemahaman agar dapat mencapai hasil yang positif pula. Suprayitno (2011), juga menemukan bahwa partisipasi masyarakat dalam mengelolah hutan kemasyarakatan adalah kurangnya keterlibatan dan keberdayaan maupun kemampuan masyarakat dalam memanfaatkan hasil hutan. Sebagian diantaranya adalah dipengaruhi oleh kurangnya motivasi untuk melaksanakan program secara keseluruhan karena pelibatan dari tahap perencanaan dan pelaksanaan mereka tidak mendapatkan informasi yang cukup.

\section{Tahap Evaluasi}

Tahapan evaluasi menjadi tahapan terakhir dalam menilai partisipasi masyarakat dalam mengelolah Hkm Tandung Billa. Tahap evaluasi adalah kegiatan evaluasi hasil kegiatan program dilihat dari aspek keterlibatan mereka dalam penyusunan pedoman pengendalian, pengumpulan data mengenai keterlibatan petani dalam perencanaan, dan pelaksanaan dan evaluasi disesuaikan dengan petunjuk teknis program (Nandini. 2013). Pada penelitian ini di dapatkan informasi bahwa proses evaluasi program kerja dilakukan setiap seminggu satu kali dan juga dilakukan evaluasi tahunan. Namun pada penjabaran penelitian ini tahap evaluasi yang dimaksud adalah tahap evaluasi untuk keseluruhan kegiatan. Hal ini disebabkan karena anggota kelompok tani yang aktif selama tahap pelaksanaan hanya 35 orang dari total 137 anggota kelompok tani hutan.

Adapun capaian dalam evaluasi ini seperti:

- Tingkat Pemahaman

Tingkat pemahaman adalah kemampuan
Witno, Maria, Dicky Supandi

(Partisipasi Masyarakat Dalam ...)

individu untuk memahami secara luas yang

berarti mencakup pengertian dasar dan tujuan program ini dilaksanakan. Dari hasil wawancara dengan Ketua GAPOKTAN secara umum dapat disimpulkan bahwa pemahaman masyarakat / kelompok tani dalam pengelolaan Hkm masih kurang. Pemahaman tentang pengelolaan $\mathrm{Hkm}$ masih membutuhkan SDM yang unggul untuk mengelolah HKm (Reski et. al. 2017).

\section{- Kesempatan}

Kesempatan adalah peluang waktu yang diberikan oleh pelaksana pengelolah kepada masyarakat untuk terlibat langsung dalam pelaksanaan pengelolaan $\mathrm{HKm}$. Adapun bentuk kesempatan yang di berikan seperti adanya ijin mengelolah hutan secara lestari, pemberdayaan masyarakat sekitar hutan, pendapatan dan perekonomian masyarakat tidak menentu, tidak ada lagi illegal loging dan perburuan satwa dilindungi (Rosalia et.al 2016). Kesempatan masyarakat pada tahap evaluasi adalah kurangnya keterlibatan masyarakat dalam melaksanakan pengelolaan di Hutan Kemasyarakatan.

\section{- Sikap}

Sikap masyarakat dalam tahap evaluasi adalah banyak masyarakat yang tidak hadir atau tidak aktif dalam rapat evaluasi. Selain itu, rasa tanggung jawab dan kepedulian juga kurang, dilihat dari jumlah pelaksana program kerjanya beberapa orang saja yang konsisten hingga akhir. Anggota kelompok tani pada setiap KUPS kurang disiplin yang berdampak pada pekerjaan yang terbengkalai dan seadanya.

Bentuk partisipasi masyarakat dalam
pengelolaan perencanaan, pelaksanaan dan evaluasi beragam. Dari uraian sebelumnya dengan memperhatikan beberapa faktor pendorong diantaranya faktor pemahaman, kesempatan dan sikap didapatkan informasi bahwa pada tahap perencanaan tingkat partisipasi masyarakat tergolong tinggi. Hal ini dilihat dari jumlah anggota masyarakat yang terlibat dalam penysusunan dan perencanaan program cukup tinggi, yaitu 137 orang. Sedangkan tahap pelaksanaan dan evaluasi tergolong rendah, disebabkan jumlah yang bergerak dan 
Volume 2 Nomor 2 Desember 2020:35-42

berpartisipasi dalam pelaksanaan program hingga tahap evaluasi hanya berjumlah 35

orang. Berdasarkan pada faktor-faktor pendorong partisipasi masyarakat menjadi tolak ukur keberhasilan program. Dengan pelibatan secara penuh kepada masyarakat dan tanggung jawab maka program bisa berjalan dengan stabil dan sebaliknya. Selain itu, prinsip partisipasi menuntut keaktifan masyarakat anggota pelaksana pengelolaan hutan berbasis masyarakat untuk memperhatikan aspek ekologi, ekonomi dan sosial budaya, jika tidak maka pelaksanaan program tidak akan optimal (Harris, 2000).

Partisipasi masyarakat dalam pemanfaatan hutan kemasyarakatan dapat dilihat dari keterlibatan masyarakat dalam kelompok tani hutan. Pada pengelolaan Hkm Tandung Billa, melibatkan 9 KUPS yang diharuskan untuk menjaga kelestarian kawasan hutan yang dikelolahnya. Memadukan kemampuan, mendayagunakan peran serta masyarakat diselaraskan dengan upaya penekanan laju kerusakan hutan dan lahan, diprioritaskan pada hutan dan lahan kritis yang menimbulkan daya rusak besar, diterapkan sistem monitoring dan evaluasi terbuka.

Peran aktif masyarakat tentu saja merupakan modal utama bagi pelaksanaan program ini. Begitu juga dalam hal distribusi manfaatnya. Kelompok tani sebagai pendamping dalam melakukan belajar bersama di berbagai bidang seperti teknologi dan produksi, pelatihan teknis sistem usaha tani, pengembangan kelembagaan dan sistem informasi. Bahkan lebih jauh dalam hal bantuan atau kerjasama permodalan. Partisipasi masyarakat dalam pemanfaatan hutan secara lestari sangat dibutuhkan, aspek-aspek kunci pembangunan berkelanjutan meliputi pemberdayaan masyarakat lokal, swasembada dan keadilan sosial. Banyak alasan dapat diberikan untuk menyertakan masyarakat dalam pengelolaan lingkungan dan sumberdaya, salah satunya yang cocok diterapkan adalah melibatkan masyarakat.

\section{KESIMPULAN DAN SARAN}

Partisipasi masyarakat dalam pengelolaan Hutan Kemasyarakatan (Hkm) Tandung Billa tergolong rendah. Beberapa faktor yang menyebabkan yaitu kurangnya keterampilan,

pengalaman dan kesempatan anggota dalam pengelolaan KUPS. Kondisi ini diperoleh dari partisipasi masyarakat dalam perencanaan berjumlah 137, pelaksanaan hingga tahap evaluasi berjumlah 35 orang. Pihak Dinas Kehutanan perlu meningkatkan sosialisasi kepada kelompok tani, sehingga seluruh anggota kelompok tani lebih sadar dan timbul rasa memiliki bahwa $\mathrm{Hkm}$ akan membawa manfaat bagi mereka, lingkungan mereka, bahkan negara, Perubahan kebijakan penyelenggaraan pembuatan hutan kemasyarakan perlu dilakukan, sehingga keterlibatan masyarakat mendapatkan porsi yang lebih dari sekarang.

\section{DAFTAR PUSTAKA}

Arikunto, S. 2006. Prosedur Penelitian Suatu Pendekatan Prakter. Jakarta: Rineka Cipta

Ayudanti, K. 2017. Analisis Efektivitas Hutan Kemasyarakatan Dalam Meningkatkan Pendapatan Dan Tingkat Konsumsi Masyarakat Menurut Perspektif Ekonomi Islam (Studi Pada Hutan Kemasyarakatan Di Kabupaten Lampung Barat) (Doctoral Dissertation, Uin Raden Intan Lampung).

Birgantoro, B. A., \& Nurrocmat, D. R. 2007. Pemanfaatan sumberdaya hutan oleh masyarakat di KPH Banyuwangi Utara. Jurnal Manajemen Hutan Tropika, 13(3), 172-181.

Departemen Kehutanan dan Perkebunan. 2014. Undang-undang no 41 Tahun 1999 Tentang Kehutanan. Salinan Kepala Biro Hukum dan Organisasi. Dephutbun. Jakarta.

Harris, JM. 2000. Basic principle of sustainable development. Global development and environment working paper. 00-04:124. Medford (US): Tufts University.

Nandini, R. 2013. Evaluasi pengelolaan Hutan Kemasyarakatan $(\mathrm{HKm})$ pada hutan produksi dan hutan Lindung di Pulau Lombok. Jurnal penelitian hutan tanaman, 10(1), 43-55.

Reski, N. A., Yusran, Y., \& Makkarennu, M. 
2017. Rancangan Pemberdayaan Masyarakat pada Pengelolaan Hutan

Kemasyarakatan (HKm) Desa Pacekke, Kecamatan Soppeng Riaja, Kabupaten Barru, Sulawesi Selatan. Jurnal Hutan dan Masyarakat, 9(1), 37-43.

Rosalia, F., \& Ratnasari, Y. 2016. Analisis Pengelolaan Hutan Kemasyarakatan Di Sekitar Kawasan Hutan Lindung Register 30 Kabupaten Tanggamus Provinsi Lampung Tahun 2010. Sosiohumaniora, 18(1), 32-36.

Ruhimat, I. S. 2013. Model peningkatan partisipasi masyarakat dalam implementasi kebijakan kesatuan pengelolaan hutan: studi kasus di $\mathrm{KPH}$ model Kabupaten Banjar, Kalimantan Selatan. Jurnal Analisis Kebijakan Kehutanan, 29263.

Safe'i, R., Febryano, I. G., \& Aminah, L. N. 2018. Pengaruh keberadaan Gapoktan terhadap pendapatan petani dan perubahan tutupan lahan di Hutan Kemasyarakatan. Sosiohumaniora, 20(2 ), 109-114.

Sanjaya, R. 2016. Evaluasi pengelolaan Hutan Kemasyarakatan (Hkm) pada Gabungan Kelompok Tani Rukun Lestari Sejahtera di Desa Sindang Pagar Kecamatan Sumberjaya Kabupaten Lampung Barat.

Sagita, M. N., Akhbar, A., \& Muis, H. 2019. Partisipasi Petani Dalam Pengelolaan Hutan Kemasyarakatan Di Desa Labuan Toposo Kecamatan Labuan Kabupaten Donggala. Jurnal Warta Rimba, 7(2).

Sugiyono. 2009. Metode Peneliitan Bisnis, Alfabeta: Bandung.

Sugiyono. 2015. Metode Penelitian Kuantitatif, Kualitatif dan $\mathrm{R}$ \& $\mathrm{D}$. Bandung:
Witno, Maria, Dicky Supandi

(Partisipasi Masyarakat Dalam ...)

Alfabeta.

Suprayitno AR, 2011. Model peningkatan partisipasi petani sekitar hutan dalam mengelolah hutan kemiri rakyat (Kasus pengelolaan hutan kemiri kawasan pegunungan bulusaraung kabupaten marosprvinsi suawesi selatan). Disertasi]. Bogor (ID): IPB.

Sudarko. 2012. Tingkat kemampuan anggota kelompok tani dalam penerapan inovasi teknologi usahatani kopi rakyat. Jurnal sosial ekonomi pertanian. 6(1): 1-10 Bandung: Alfabeta.

The British Council. 2001. Teknik mewujudkan partisipasi masyrakat London. British Council.

Undang-Undang Republik Indonesia Nomor4Tahun $1982 \quad$ Tentang Ketentuan-Ketentuan Pokok Pengelolaan Lingkungan Hidup

Winata, N. G. A. W., Basuki, P., \& Karismawan, P. 2015. Analisis Determinan Pendapatan Petani Program Hutan Kemasyarakatan (HKm) di Kecamatan Batukliang Utara Kabupaten Lombok Tengah. Jurnal Sosial Ekonomi dan Humaniora, 1(1).

Yudischa, R., Wulandari, C., \& Hilmanto, R. 2014. Dampak partisipasi wanita dan faktor demografi dalam pengelolaan hutan kemasyarakatan (hkm) terhadap pendapatan keluarga di kabupaten lampung barat. Jurnal Sylva Lestari, 2(3), 59-72.

Zeilika, E. 2020. Partisipasi Petani Dalam Pengelolaan Hutan Kemasyarakatan Studi Kasus Gapoktan Mandiri Lestari Di Kesatuan Pengelolaan Hutan Batutegi. 